\author{
Mauro Brigeiro \\ Universidad Nacional de Colombia
}

Ivia Maksud

Universidade Federal Fluminense

\title{
Aparição do Viagra na cena pública brasileira: discursos sobre corpo, gênero e sexualidade na mídia
}

Resumo: Este trabalho propõe uma reflexão antropológica sobre os discursos e imagens do corpo e da sexualidade na sociedade brasileira com base em um fenômeno social particular: o surgimento do Viagra na esfera pública nacional. Explora as conotações construídas e/ou ratificadas pela mídia impressa em torno deste medicamento, a partir da análise de conteúdo de reportagens publicadas em dois jornais de grande circulação, pertencentes à mesma organização empresarial e dirigidos a públicos distintos. O material analisado data de abril de 1998 a abril de 1999, período correspondente ao início - e ápice - do debate sobre o medicamento no país. O artigo trata dos simbolismos e das estratégias discursivas utilizadas pelos jornais na apresentação do remédio para o público geral e chama a atenção para um apelo a lógicas tradicionais de gênero, a despeito de um cenário contemporâneo de questionamentos acerca das relações entre os sexos e da sexualidade.

Palavras-chove: medicalização da sexualidade; gênero; corpo; envelhecimento; mídia.

Copyright (c) 2009 by Revista Estudos Feministas.

${ }^{1}$ Michel FOUCAULT, 1977, p. 16.

\begin{abstract}
[...] o ponto essencial [é] [...] levar em consideração o fato de se falar de sexo, quem fala, os lugares e os pontos de vista de que se fala, as instituições que incitam a fazê-lo, que armazenam e difundem o que dele se diz, em suma, o 'fato discursivo' global, a 'colocação do sexo em discurso'. Daí decorre também o fato de que o ponto importante será saber sob que formas, através de que canais, fluindo através de que discursos o poder consegue chegar às mais tênues e mais individuais condutas. [...] de que maneira o poder penetra e controla o prazer cotidiano. ${ }^{1}$
\end{abstract}

\section{Introdução}

${ }^{2}$ Agradecemos a Paulo Eugênio Clemente Jr., Mara Viveros e Franklin Gil pela leitura atenta e contribuições a este texto. Aos pareceristas da Revista Estudos Feministas somos muito gratos pelas pertinentes sugestões.
A chegada do Viagra ao mercado brasileiro foi precedida e acompanhada por ostensiva promoção por parte dos meios de comunicação de massa, o que, independentemente das intenções ou jogos de interesses 
${ }^{3} \mathrm{Em}$ relação às representações sobre o consumo do Viagra, ver o trabalho de Rogério AZIZE, 2004. da indústria farmacêutica, contribuiu decisivamente na elaboração de significados sociais em torno do medicamento. Observando as matérias jornalísticas sobre a 'pílula azul', identifica-se rapidamente uma intensa produção discursiva e de imagens sobre corpo e subjetividade moderna. Uma análise social sobre esse fato justifica-se pela incitação ao consumo do remédio propagada pelos jornais e pela normatização do exercício sexual e seu caráter catalisador de problemas e situações sociais contingentes ou não à esfera da sexualidade e da saúde.

Este artigo trata do delineamento das lógicas simbólicas criadas ou 'reeditadas' na aparição pública do Viagra, entendida aqui como um fato social paradigmático sobre as formas como são reelaboradas as concepções de corpo, sexualidade e bem-estar nas sociedades contemporâneas. O percurso metodológico da investigação realizada envolveu a recuperação, sistematização e análise das matérias sobre o Viagra na mídia impressa ao longo de um ano. As fontes são dois jornais de uma mesma organização empresarial dirigidos a públicos distintos, voltados respectivamente para membros dos segmentos populares e das camadas médias. A análise permite apreender as estratégias e recursos discursivos que elevaram o Viagra a um tema social de primeira ordem, trazendo à cena pública os dramas íntimos das 'falhas sexuais', a proposta de plasticidade corporal, o cenário das relações de gênero e as vicissitudes da vida conjugal e do envelhecimento, em um entremeado discursivo que encontrou eco nas lógicas culturais da vida cotidiana brasileira.

O material examinado constitui-se de reportagens que fazem referência direta ou metafórica ao Viagra, entre $1^{\circ}$ de abril de 1998 e $1^{\circ}$ de abril de 1999. Tal delimitação temporal não é aleatória, pois nesse período surge o medicamento (conforme será abordado mais adiante) e ocorrem intensa divulgação e debate na sociedade brasileira. O Viagra surge publicamente no país bem antes de sua distribuição no mercado, circula virtualmente por mais de três meses antes de se tornar um objeto de consumo concreto e é a mídia que lhe confere essa existência. Durante algum tempo ela possibilita um contato estreito entre a sociedade e o remédio, que se torna assim uma realidade de domínio comum antes mesmo de ser experimentado pelas pessoas. Sem a abordagem midiática, ou seja, baseado na prescrição clínica pura e simplesmente, possivelmente o medicamento não teria o mesmo reconhecimento social que adquiriu.

Não pretendemos analisar o Viagra como um bem em si mesmo ou suas relações com os consumidores, ${ }^{3}$ mas tomar o discurso jornalístico como plataforma privilegiada 
${ }^{4}$ Sergio ADORNO, 1998.

${ }^{5}$ Pierre BOURDIEU, 1986.

- Claudine HERLIZCH e Janine PIERRET, 1998; e Mike HEPWORTH e Mike FEATHERSTONE, 1999.

de debate sobre aspectos concernentes à cultura sexual brasileira. Se é possível afirmar que o discurso midiático 'traduz' a vida cotidiana, resgatando simbolismos existentes em determinados contextos, ${ }^{4}$ também é verossímil dizer que os meios de comunicação produzem significados através das informações que veiculam, propondo novos valores e hierarquias de práticas sociais e detendo um locus privilegiado pela lógica de mercado. ${ }^{5}$ Para entender a abordagem do Viagra pelos veículos importa considerar, sobretudo, a ideia de que os meios de comunicação de massa, juntamente com as comunidades científicas, atuam como entidades mediadoras privilegiadas nos processos de constituição de um problema social. ${ }^{6}$ Em outras palavras, pretendemos sublinhar a eficácia dos seus discursos na construção ou reforço de sensibilidades sociais ao redor de um novo objeto.

As matérias foram coletadas em dois jornais cariocas de grande circulação - Extra e O Globo - pertencentes à mesma organização empresarial, mas destinados a públicos diferenciados. De um banco de dados de 2.815 reportagens que versavam sobre o tema da sexualidade ou aludiam a ele de alguma forma, selecionaram-se 138 registros sobre o

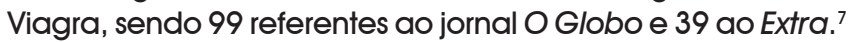
Foram analisados todos os espaços dos jornais, com exceção dos anúncios pagos e dos cadernos de classificados, viagens, de informática e de automóveis. Não se elegeu uma coluna ou caderno específico para o exame. Essa medida foi tomada a partir da constatação da existência de matérias sobre o medicamento em várias seções e colunas dos jornais.

A identificação dos públicos de cada jornal é dada a priori pelos próprios veículos, por uma lógica de classificação mercadológica que divide os segmentos de leitores a partir de seu potencial de compra. Com base em estudos que examinam jornais, ${ }^{8}$ utilizamos as denominações de "jornais populares" e "jornais cultos" visando chamar a atenção para as diferenças simbólicas entre as classes sociais conferidas pelos meios de comunicação. Entre suas diferenças destacam-se a linguagem e a forma de apresentação ou tratamento dos temas, apropriadas e específicas a cada público leitor.

A análise do material toma como parâmetro o enfoque antropológico. Interpretamos as reportagens seguindo o método de análise de conteúdo e de relações de oposição. Sob esse enfoque, sistematizamos as categorias recorrentes nos discursos e privilegiamos, por um lado, a conotação das frases e, por outro, os sentidos implícitos nas afirmações e negações em jogo. ${ }^{9}$ Consideramos os diferentes espaços dos jornais, o tipo de linguagem adotada, os

9 Alain BLANCHET e Anne GOTTMAN, 1992. 
${ }^{10}$ Programa Globo Repórter, Rede Globo, 28 de maio de 1998.

11 Jane GALVÃO, 2000. argumentos e recursos imagéticos utilizados e, especialmente, as representações acionadas pelos veículos. Ao buscar os princípios que estruturam esses discursos, observamos as particularidades de abordagens, os elementos iconográficos e os recursos linguísticos privilegiados nas matérias jornalísticas.

\section{O Viagra como um fato paradigmático}

Uma das maiores frustrações do homem é a insatisfação sexual. De repente um comprimido vem e diz: vai ser feliz, homem! Vai ser feliz, humanidade! Vai se realizar, homem! Vai se realizar, mulher! Como é que eu não vou elogiar esse comprimido?

O depoimento acima foi expresso efusivamente por um dos cronistas mais populares do Rio Grande do Sul Paulo Santana - no programa de televisão Globo Repórter. ${ }^{10}$ Como indica a reportagem, o jornalista ficou tão impressionado com o resultado do remédio que publicou sua experiência no Zero Hora, um importante jornal do estado. O caso mencionado e tantos outros que perduraram vários meses como tema central de debate na mídia evidenciam que em torno do Viagra se construiu um fato social paradigmático.

Nenhum outro medicamento havia sido abordado na mídia impressa brasileira com a mesma expressividade e variedade de sentido, generalizando-se em seções e colunas tão diversas. Os tratamentos de reposição hormonal para as mulheres na menopausa, o Prozac, para pessoas com depressão, e até mesmo a disponibilização gratuita dos medicamentos antirretrovirais para o tratamento das pessoas infectadas com o vírus da AIDS no Brasil, atualmente considerados a resposta clínica mais eficaz alcançada contra a epidemia, não geraram atenção igual dos meios de comunicação, ainda que a AIDS, sobretudo nos anos iniciais da epidemia, tenha recebido grande destaque nestes. ${ }^{11}$

As informações sobre o Viagra se propagaram com uma velocidade extraordinária em vários segmentos da sociedade brasileira. Três argumentações ajudam a compreender a proeminência alcançada. A primeira está relacionada ao fator mercadológico e à atuação publicitária das empresas farmacêuticas, enfáticos na estratégia de lançamento do produto; a segunda aponta a especificidade desse medicamento diante de outros tratamentos (cirúrgicos e psicológicos) para impotência sexual; e a terceira está condicionada ao caráter particular da cultura sexual brasileira. Explicamos cada uma a seguir. 
12 As indústrias farmacêuticas, como as demais empresas atualmente, baseiam sua expansão por meio da inovação constante de seus produtos e pela forte publicidade. Segundo Yves ENGLER, 2003, o dinheiro gasto pelo mercado das drogas em promoção de medicamentos nos Estados Unidos no ano de 2001 superou a cifra de 16 bilhões de dólares apenas em atividades de divulgação junto a médicos e estudantes. O autor descreve que a promoção dos medicamentos junto aos profissionais de saúde consiste em diferentes estratégias como visitas de representantes de venda (geralmente mulheres bonitas), distribuição de amostras grátis, brindes, convites a cerimônias, treinamentos, apoios a eventos científicos, etc. Como exemplo, cita o caso do Viox, cujo laboratório (Merck) despendeu mais de 161 milhões de dólares em divulgação nos Estados Unidos em 2000; superando o que investiu a Pepsi, empresa do ramo alimentício, em publicidade no mesmo ano (125 milhões de dólares).

${ }^{13}$ Alain GIAMI, 1998.

${ }^{14}$ BOZON, 2004, p. 146.

${ }^{15}$ Natalie BAJOS e Michel BOZON, 1999.

16 Ambos os meios analisados (especialmente o jornal culto no qual se atribuiu um maior número de interlocutores qualificados a falar do tema) serviram de veículo para as explicações médicocientíficas sobre as falhas sexuais. Ainda assim, não se identificou nos jornais uma adesão especial à categoria "disfunção erétil". Mais adiante voltaremos a esse tema. De todo modo, definitivamente, a intensa promoção desse remédio orientou o problema da impotência sexual masculina para o campo das doenças e sua cura para o domínio da biomedicina.

17 Somente um dos registros do jornal culto registra o depoimento de dois urologistas defendendo a pertinência do uso das próteses penianas e sua indicação para casos em que o paciente não tivesse nenhuma possibilidade de
Além dos jornais, a televisão, o rádio e a Internet dedicaram-se a difundir muitas e variadas reportagens sobre o medicamento. Não poderia ser diferente, afinal o reconhecimento que desfrutam as novas tecnologias biomédicas na atualidade está diretamente associado às estratégias publicitárias para sua divulgação. ${ }^{12} \mathrm{O}$ caso do Viagra traz uma característica peculiar: a proposta de influenciar o público a agir em direção a uma busca de melhor qualidade para a atividade sexual. ${ }^{13}$ Autores franceses como Michel Bozon e Alain Giami demonstram que o laboratório que produziu o Viagra - Pfizer - dirigiu suas campanhas tanto aos médicos quanto diretamente ao grande público, direcionando os homens aos consultórios médicos no caso de problemas de ereção. Segundo Bozon,

O entusiasmo dos homens por uma atenção individual, rápida e eficaz [...] tornou-se o motor da 'patologização' do distúrbio erétil e do sucesso do produto, antes mesmo da mudança nas atitudes dos médicos. E assim, a demanda pelo produto 'cria' a disfunção. ${ }^{14}$

Para esses autores, o Viagra teria corroborado para a transformação das definições médicas, que passaram de uma preocupação com o problema da "impotência sexual" para uma concepção de "disfunção erétil", modificando a visão etiológica do fenômeno. ${ }^{15}$ As causas associadas a fatores psíquicos perderam relativa importância diante de fatores orgânicos e/ou ligados ao envelhecimento. Operase uma separação do problema em relação às suas causas mais convencionais. O fenômeno da "disfunção erétil" traz como novidade vários tipos de disfunções que até então não apareciam socialmente como um problema ou uma patologia. Dessa forma, a divulgação de estudos sobre impotência sexual para um vasto público possibilitou ampliar o mercado potencial do remédio. ${ }^{16}$

Comparativamente a outras ofertas de tratamento, 0 Viagra se apresenta publicamente como uma das formas mais eficazes já produzidas contra a impotência sexual. 0 tratamento medicamentoso surge como mais eficaz que as abordagens psicológicas, e a terapêutica da "disfunção erétil" encontra um lugar por excelência na clínica médica, dada a simplicidade de manejo e velocidade da sua resposta. As alternativas de tratar o 'problema' através de injeções ou cirurgicamente, por meio da implantação de próteses, tornam-se também menos atraentes com a introdução do Viagra. ${ }^{17}$

Tomando o caso brasileiro, a especificidade da cultura sexual nacional - ou os modos como ela é construída/ confirmada - possibilitou uma ampla disseminação desse 
irrigação sanguínea para o pênis. $O$ restante das matérias enaltece as vantagens do Viagra em relação a procedimentos mais longos, dolorosos ou incômodos.

${ }^{18}$ Cabe ressaltar que, de acordo com BOURDIEU, 2000, o lançamento do medicamento na Europa e nos Estados Unidos também gerou grande repercussão social. No mesmo sentido, em países de economia emergente como a China, o Viagra teve um alto consumo, evidenciando uma tendência de adesão ao 'hedonismo capitalista' (Judith FARQUHAR, 2002).

${ }^{19}$ Roberto DA MATTA, 1983; Richard PARKER, 1991; e Mauro BRIGEIRO, 2000.

${ }^{20}$ De acordo com sexólogo consultado pelo jornal culto, "... brasileiro é louco por sexo, e por isso não vai ler a bula", e dessa forma o remédio seria apropriado como um afrodisíaco.

${ }^{21}$ Manchete de jornal popular, a algumas semanas antes da liberação do Viagra para a venda.

$22 \mathrm{O}$ jornal culto chega a veicular que naquele país, apenas no primeiro mês, foram realizadas mais de duas mil prescrições do remédio. Uma semana depois, o mesmo jornal atualiza a cifra em 600 mil. medicamento na vida cotidiana. ${ }^{18}$ Resgatando uma imagem de brasileiro extremamente sexualizado e apostando na ideia de 'sacanagem' como valor que funda essa identidade, ${ }^{19}$ o Viagra tornou-se um assunto recorrente e banal nos mais diferentes espaços sociais da época. Os discursos jornalísticos tomaram como foco os corpos sexuados - especialmente o masculino -, ressaltaram a importância da sexualidade na vida diária e promoveram um questionamento acerca das relações amorosas. Ademais, evocaram discussões antigas sobre a voracidade e o excesso sexual do brasileiro. ${ }^{20} \mathrm{Em}$ torno desse medicamento armou-se um palco de discussões e piadas sobre sexo, deslocando da esfera privada para a arena pública temas tradicionalmente não presentes, de modo tão ostensivo, nos veículos de comunicação.

\section{Enquanto o Viagra não vem ${ }^{21}$}

Como dito anteriormente, no Brasil o Viagra transformou-se em um acontecimento social antes mesmo de chegar às prateleiras das farmácias e às mãos do consumidor. Curiosamente, desde suas primeiras aparições nos jornais, o remédio ocupou um lugar de destaque diante de outras notícias e tornou-se um tema que transitava pelas diferentes seções e colunas; constante nas áreas de saúde, ciência e tecnologia, como também nas áreas de economia, política, esportes, variedades e entretenimento. Tornouse o 'assunto do momento' e assim perdurou por vários meses.

Sistematizando cronologicamente os registros levantados na mídia impressa, podemos dividi-los em dois períodos: antes e depois da liberação do medicamento para comercialização no Brasil. Ao ser introduzido no cenário nacional, o remédio evoca sua primeira polêmica: a autorização do Ministério da Saúde para seu consumo e venda.

As primeiras reportagens surgem em março de 1998, indicando a descoberta de um novo medicamento que revolucionaria a vida sexual das pessoas, tal como a pílula anticoncepcional dos anos 60. As matérias informam que o remédio foi aprovado pelo Food and Drug Administration (FDA) nesse mesmo mês e liberado para consumo e comercialização nos Estados Unidos em abril de 1998, ou seja, no mês seguinte. O destaque das reportagens no período é que o Viagra se tornou um sucesso de vendas no mercado americano. ${ }^{22}$

Os meios também advertem sobre possíveis efeitos colaterais. Algumas matérias apresentam casos de morte por consumo do medicamento e os laboratórios farmacêuticos argumentam que esses casos seriam decorrentes de 'mau uso do remédio'. As representações de risco para a 
saúde e perigo de morte não aparecem isoladamente; estão acompanhadas de uma série de imagens que, enaltecendo seus efeitos positivos e reforçando a infelicidade de um mau desempenho sexual, exibem o consumo do Viagra como um risco compensatório. Uma manchete do jornal popular informa jocosamente que "Cidadão morre feliz por overdose de tesão".

O bombardeio de informação, não apenas jornalísticas, mas também de outros meios de comunicação, parece ter favorecido a aprovação do medicamento para consumo e comercialização no Brasil. Os trâmites para sua liberação comercial duraram pouco mais de um mês, a contar das primeiras reportagens. Informava-se, sobretudo, que o Viagra já estava sendo consumido por brasileiros em viagens ao exterior ou por meio de importação. O medicamento era apresentado como uma mercadoria extremamente valorizada socialmente, com alta conotação no mercado econômico. A ansiedade pelo consumo gerou inclusive contrabando, segundo as reportagens da época que, inclusive, exigiam taxativamente uma resposta das autoridades. Há notícias revelando apreensão de cargas ilegais no Brasil, 'mercado negro', etc. Argumentava-se também que, uma vez não aprovado no país, o risco de falsificação seria grande. Foi recorrente, nesse período, que os jornais apresentassem o perfil do consumidor do Viagra como um homem que viajava constantemente ao exterior ou um homem abastado financeiramente a ponto de adquirir o medicamento a preços mais altos, por importação. Tais imagens, construídas nos dois jornais, sugerem um modelo hegemônico de masculinidade baseado nos empresários, executivos e burocratas que viajam com frequência, estão em dia com as novas tecnologias e desfrutam de prazeres que não encontram limites a serem controlados pelas nações

${ }^{23}$ Robert CONNEL, 1998. às quais pertencem. ${ }^{23} \mathrm{~A}$ título de ilustração, reproduzimos uma chamada no jornal popular com o seguinte trocadilho: "O Viagra não é coisa para duro".

Ao chegar ao mercado brasileiro, o Viagra já era amplamente conhecido, não apenas por seu nome, mas por seus possíveis efeitos, benéficos e maléficos. Sua entrada oficial no país, ou seja, após liberação pelo Ministério da Saúde, é datada de $1^{\circ}$ de junho de 1998, uma segundafeira. Um dia antes, os jornais de domingo deram grande repercussão ao fato, com reportagens de até duas páginas, contendo informações sobre utilização da pílula e conselhos de especialistas de saúde (urologistas, farmacêuticos, cardiologistas, andrologistas, sexólogos, psicólogos e psicanalistas). O conteúdo dos jornais também enfocava a mobilização em torno das filas de espera para a compra e 
${ }^{24} \mathrm{O}$ uso desse tipo de publicidade seguramente está relacionado à agressiva estratégia de venda proposta pelo laboratório que o produziu. Na ocasião, em outros países como a Colômbia, farmácias também afixaram placas com dizeres similares.

${ }^{25}$ De fato, alguns meses depois, um registro do jornal popular informava que uma quadrilha invadiu uma grande drogaria no centro do Rio de Janeiro, roubando diferentes medicamentos. A matéria dá ênfase ao Viagra na chamada e no texto.

${ }^{26}$ À exceção desse dia, nas tiragens seguintes todos os registros indicavam que o remédio foi um sucesso de vendas. as possibilidades de descontos. Anunciava-se a existência de lista de reservas nas drogarias.

Na segunda-feira, os jornais mostravam que os donos de farmácias já haviam organizado as prateleiras durante o fim de semana e, em alguns estabelecimentos, a venda começara dias antes da liberação oficial. Farmácias com o medicamento exibiam placas informando "Temos Viagra". ${ }^{24}$ O sucesso de vendas ocorrido nos Estados Unidos era apresentado nos jornais como um fato seguro a repetirse no Brasil. Autoridades como a presidente do Conselho Regional de Farmácia do Rio de Janeiro, alertando sobre as sanções para venda irregular, confirmavam o êxito de vendas: "A Vigilância Sanitária só autorizou a venda do Viagra a partir dessa segunda-feira. As farmácias já estavam vendendo o remédio importado ilegalmente. Com a liberação vai ser uma festa..." (jornal culto). Donos de drogarias eram unânimes em afirmar que o lançamento do Viagra fora o maior já visto no país até então, superando o abastecimento habitual das farmácias. Outra curiosidade do período: acentuando o alto valor conferido ao medicamento, os discursos da mídia ressaltavam que os nomes das distribuidoras oficiais seriam mantidos em sigilo por receio de que assaltantes interceptassem cargas destinadas às farmácias. ${ }^{25}$

Após a liberação para vendas, a principal preocupação ao redor do Viagra parecia ser o consumo sem indicação médica. A prescrição médica era condição para a comercialização e venda. Entretanto, os jornais utilizavam um duplo discurso. Ao mesmo tempo que advertiam sobre os perigos de ingerir o medicamento sem prescrição, indicavam que o controle e a vigilância sanitária deixariam muitas brechas para o consumo indiscriminado e a autoadministração: "A falta de fiscalização será a grande aliada das farmácias, mas também poderá ser um inimigo dos compradores mais afoitos" (jornal culto).

Sob o título "Cautela inibe a venda do Viagra", o jornal culto dedica uma matéria de página inteira ressaltando que nos Estados do Rio de Janeiro e São Paulo o saldo de vendas no primeiro dia não correspondeu às expectativas e que houve muitas perguntas e poucas compras: "Não registrou o movimento esperado pelos donos de farmácias. Em compensação, não faltou gente com perguntas sobre o preço e as características do remédio". ${ }^{26}$ As reportagens constroem suas justificações em torno da baixa procura do Viagra no primeiro dia de vendas. A compra do Viagra é descrita como um comportamento vergonhoso e relata-se que muitos homens chegaram às drogarias alegando que o produto seria para outra pessoa. As matérias validam a necessidade do remédio, ao mesmo tempo que reconhecem 
o estigma de quem o necessita. Seu consumo estaria associado à ausência de um atributo de gênero esperado, que não pode ser assumida em espaços públicos. "Em geral os interessados esperavam que o balcão ficasse vazio para fazer o pedido em voz baixa" (jornal culto). Ainda assim, segundo as reportagens, os homens foram os que mais apareceram para comprar o medicamento, enquanto as mulheres telefonavam para pedir informações. Uma das reportagens destaca o "Disque Viagra" como uma alternativa de venda por telefone. Dessa forma, preservava o anonimato do comprador, reforçando o caráter simbólico de constrangimento associado à não-virilidade. Nesse sentido, a apresentação do Viagra opera uma relação paradoxal na qual há que se superar a perda da virilidade sem demolir seu conteúdo simbólico (ao contrário, reforçando-o).

\section{Indicações e contraindicações}

Os discursos dos jornais sobre o Viagra tiveram a função primordial de elevá-lo a tema social de primeira ordem e evocar, à luz pública, os dramas íntimos das falhas sexuais. Sem dúvida, trata-se de um excelente exemplo sobre as formas como as concepções do corpo e da saúde/bemestar são reelaboradas nas sociedades contemporâneas. Tais discursos enaltecem a atividade sexual como uma importante fonte de felicidade para os sujeitos, assinalando a centralidade da penetração e da ereção, ora reforçando a medicalização da sexualidade, ora destacando a ideia de juventude eterna, e evocando a ideia de plasticidade corporal: um corpo plástico, moldável para a satisfação dos desejos.

A princípio, o Viagra seria um medicamento criado para os homens e, segundo depoimentos de especialistas consultados, com indicações e contraindicações bem delimitadas. O medicamento seria indicado para homens acima de 40 anos, vetado a pacientes hipertensos, diabéticos ou com problemas cardíacos.

Apesar da diversidade de usos auferida, algumas matérias afirmam, valendo-se de jargões biomédicos, que - Viagra é apenas um vasodilatador que facilita e ajuda a manter a ereção (não é um afrodisíaco aumentando a libido e desejo sexual), portanto, necessitando de engrenagem perfeita (psicológico/orgânico) desde o estímulo sexual/ resposta neurocerebral, permeabilidade vascular (artérias e veias) penianas, endotélio, corpos cavernosos (tecido erétil) intactos, sem esquecer dos fatores psicológicos... llustrações gráficas sobre a anatomia são apresentadas e o corpo masculino é esquadrinhado de forma bem detalhada. Como indicação mais geral, os jornais propagam a ideia 
${ }^{27}$ André BEJIN, 1987.

${ }^{28}$ Podemos citar inúmeros registros que ilustram a afirmação. Por exemplo, o nome do remédio muitas vezes foi citado para enfatizar a nudez e a beleza feminina. A atriz Nicole Kidman recebeu 0 título de "puro Viagra teatral" por um crítico inglês, após sua aparição nua durante a apresentação de uma peça. A notícia recebeu cobertura tanto no jornal culto como no jornal popular.

${ }^{29}$ Para BOZON, 2004, o Viagra é pensado antes como um afrodisíaco do que como tratamento, despertando nos homens o sonho de um desejo ilimitado e programável.

${ }^{30}$ No período estudado, apenas uma reportagem, datada de março de 1999 e publicada no jornal culto, noticiou um estudo em que se comprovava que o remédio não tinha um efeito orgânico, e sim psicológico, sobre as mulheres.

${ }^{31}$ Os jornais parecem resgatar, por meio dos discursos dos especialistas, a concepção do one model sex identificado por Thomas LAQUEUR, 2001, nos tratados médicos anteriores ao século XVIII. Segundo esse autor, as descrições dos cirurgiões dessa época apontavam uma concepção diferente à do dimorfismo sexual das espécies. O que existia então era um modelo sexual único com duas variações, na qual a feminina indicava um desenvolvimento rudimentar e a masculina sua forma mais completa. sexológica do orgasmo como um dever e um indicador da saúde sexual. ${ }^{27}$ Dado que a principal preocupação da sexologia é restaurar o orgasmo, o problema da impotência sexual se insere no escopo de seus interesses. Entretanto, o Viagra é quase sempre apresentado como a 'pílula do amor' ou 'pílula contra a impotência sexual', não assumindo um compromisso estrito com a classificação médica de disfunção erétil. Isso se reflete nas finalidades atribuídas ao remédio. Salvo nas aclarações feitas por médicos e sexólogos, a maioria das notas ou reportagens apresenta-o como um afrodisíaco ou estimulante que aumentaria $o$ interesse e a intensidade do ato sexual.

Nas matérias analisadas o medicamento está associado a sentimentos e sensações como vigor físico, disposição, força, energia, rejuvenescimento, decisão, vitória, precisão, risco, frisson, beleza, satisfação, saúde e, algumas vezes, ao aumento da fecundidade. ${ }^{28}$ Especialmente quando comparado com os remédios conhecidos como 'naturais', ficam patentes esses atributos. Muitas vezes ele aparece indicado ao homem que não tem problemas sexuais e que apenas gostaria de melhorar seu desempenho. ${ }^{29}$ Sobretudo, por meio das metáforas e do constante humor empregado nas matérias, algumas vezes ele é associado a um fortificante ou um elixir que revigora a atividade física.

Outra indicação presente nas reportagens e que resulta interessante destacar é o Viagra para as mulheres. Nas reportagens encontramos um conjunto de questionamentos sobre os efeitos do remédio em seus corpos, sua sexualidade e, consequentemente, em suas relações com homens. Vários estudos sobre possíveis benefícios femininos são reportados. $O$ argumento de base era que o estímulo que a droga provoca na irrigação sanguínea teria uma resposta equivalente sobre a fisiologia masculina e feminina. E se no caso dos homens facilitaria a ereção, nas mulheres ampliaria a lubrificação vaginal e a excitação do clitóris, permitindo que elas chegassem ao orgasmo. ${ }^{30}$ Encontramos aí um binômio de equivalência impotência masculinafrigidez feminina, ambas marcados por uma etiologia exclusivamente orgânica. Desse modo, os jornais constroem uma analogia dos corpos masculinos e femininos que, apesar de suas diferenças anatômicas, guardam uma correspondência no funcionamento fisiológico sexual, ao mesmo tempo que estabelecem uma importante diferenciação de gênero no que se refere às especificidades das falhas sexuais sobre as quais o medicamento pode atuar. ${ }^{31}$

Tanto a indicação do medicamento para os homens quanto a especulação científica que procurou estendê-lo 
32 BEJIN, 1987.

${ }^{33}$ HEPWORTH E FEATHERSTONE, 1999.

${ }^{34}$ BOZON, 2004.

${ }^{35}$ Como afirma Guita Grin Debert, "Disciplina e hedonismo combinam-se na medida em que as qualidades do corpo são tidas como plásticas, e os indivíduos são convencidos a assumir a responsabilidade pela sua própria aparência. A publicidade [...] e as receitas dos especialistas em saúde estão empenhados em mostrar que as imperfeições do corpo não são naturais nem imutáveis, e que, com esforço e trabalho corporal disciplinado, pode-se conquistar a aparência desejada. [...]. A suposição de que [...] aqueles que conservam seus corpos com dietas, exercícios e outros cuidados viverão mais, demanda de cada indivíduo uma boa dose de 'hedonismo calculado', encorajando a autovigilância da saúde corporal" (DEBERT, 1997, p. 42). ao consumo feminino insistiam na imagem de potencializar a atividade sexual. Sob esse aspecto, podemos identificar uma tentativa de resgatar a proposta sexológica de uma 'democracia sexual', um ideal moderno em que todos, independentemente do sexo ou da idade avançada, acederiam ao prazer sexual e à realização pessoal: o orgasmo para todos! ${ }^{32}$ Segundo essa ideia, o Viagra não estaria a serviço de manter o prazer como uma exclusividade e privilégio dos homens. Porém, cabe ressaltar que o conteúdo das matérias se dirigia mais ao público masculino e, ademais, heterossexual. Nas 138 matérias, apenas uma única menção à homossexualidade (especificamente, à prática sexual anal) é registrada em todo o corpus analisado. Nesse caso, os homossexuais masculinos não estariam excluídos de se beneficiarem com o remédio. $O$ erotismo anal é acionado e sobre ele o desejo sexual seria intensificado, porém em tom jocoso:

Leve logo isso daqui para a mulher que você ama.

Se não gosta de mulher, esse remédio não toma senão vai andar de ré daqui até Copacabana jornal popular).

Os registros identificados manejam uma linguagem comum à cultura de consumo, enfatizando uma ideia de que tudo é possível. Utilizam uma linguagem fortemente individualista na qual o sujeito, o corpo e a vida sexual são vistos como flexíveis e moldáveis. Vendem a ideia de uma plasticidade corporal segundo a qual as mudanças percebidas no corpo com o passar dos anos dependem menos das limitações fisiológicas e associam-se mais com o estilo de vida e a responsabilidade individual. ${ }^{33} \mathrm{O}$ jornal veicula a concepção de que o corpo é um veículo do prazer a da autoexpressão. Com o Viagra, seu funcionamento pode ser controlado e o ato sexual programado. ${ }^{34}$ As falhas sexuais, bem como outras qualidades do corpo, explicamse como fenômenos naturais, o que não significa necessariamente que sejam imutáveis; sua transformação está ao alcance de todos. ${ }^{35}$ Encontramos nos jornais uma justificativa das falhas sexuais apoiada em forças naturais, que tanto desloca do foco do problema as razões de ordem subjetiva, como propõe uma noção de natureza corporal domesticável no que se refere à sexualidade.

Outra faceta possível dos benefícios do remédio seria a reversão da velhice que ele viria a operar. Seja pelo sentido implícito em certas descrições, seja pelo recurso ao humor, observa-se nas notícias uma importante relação em termos de desempenho sexual e idade, segundo a qual o primeiro seria inversamente proporcional ao segundo. O remédio viria 
36 Para uma crítica detalhada sobre os discursos dos especialistas acerca do envelhecimento e da sexualidade, ver BRIGEIRO, 2000 e 2002.

37 Os jornais noticiaram vários episódios a respeito. Desde um avião que teria caído por causa de um piloto que estava sob efeitos do remédio, até o caso de um norte-americano que processou o laboratório por ter sofrido um infarto após ingeri-lo.

${ }^{38}$ Uma das reportagens anunciou que naquele dia o Viagra apareceria como tema central de um programa televisivo de grande qudiência ("Você Decide"). A história aborda um casal que vive junto há 50 anos. O marido resolve tomar o remédio e se envolve com uma jovem. Na reportagem um urologista afirma ironicamente: "o Viagra é uma ameaça para a família", e em seguida completa: "conheço pacientes que traíram suas esposas depois que tomaram a pílula". E as demais afirmações do médico sugerem outras imagens. Aconselha textualmente os homens mais velhos a cuidar-se com mulheres jovens e interesseiras que poderiam levá-los rapidamente à ruína, e a valorizar sua relação antiga, a ter cautela com os filhos, que poderiam interná-los caso discordassem do romance. Enfatiza: "quando um senhor toma o Viagra, é como se estivesse colocando o motor de uma BMW num fusca". O jornal explica: "é lógico que o homem vai ficar cheio de energia, mas não pode se iludir, porque não será um 'modelo do ano'” (jornal popular). justamente a romper com tal relação. Novamente, resgatase aqui um tópico da agenda sexológica segundo o qual o curso da vida sexual praticamente deve coincidir com o curso da vida dos sujeitos. Nesse sentido, com as ajudas biotecnológicas e pedagógicas disponíveis, a vida sexual só terminaria quando a pessoa morresse. ${ }^{36}$

Os homens velhos eram frequentemente evocados nas reportagens: "no primeiro dia de vendas a maioria dos clientes nas farmácias era da terceira idade" (jornal culto); "Terceira idade poderá ter vez ao teto espelhado" (jornal popular). Em uma charge publicada no jornal popular, as filas nas farmácias se confundem com as do INSS, e em outra um velho vestido de super-homem vai à farmácia. Tais imagens assinalam a tensão existente entre atividade sexual e velhice, apostando no medicamento como uma solução para esse 'problema'.

Mas o Viagra não está associado apenas à regeneração, cura ou recuperação. Efeitos colaterais, como os distúrbios da visão, infartos e até morte, estão relacionados ao remédio. ${ }^{37}$ Chamadas do tipo "Ereção fatal" falam da relação arriscada, mas compensatória, entre sexualidade e morte. Além disso, ao mesmo tempo que pode instaurar uma nova vida sexual, o Viagra surge como um perigo para as relações conjugais de longa data. Várias foram as reportagens que discutiram a vida dos casais a partir do medicamento. Essas reportagens tratavam do rompimento e desestruturação de relações antigas. A entrada em cena do Viagra enfatiza o sexo como valor nas relações conjugais, mesmo naquelas em que a atividade sexual não era mais considerada central. Identificaram-se diversas reportagens sobre divórcios, pedidos de indenizações à Pfizer e processos contra ex-maridos por abandono ao lar. O remédio apareceu como gerador de temor entre as mulheres, porque os homens, novamente potentes, poderiam buscar uma nova mulher. ${ }^{38}$ Com menor frequência o remédio é descrito como um reconciliador da união desgastada e uma possibilidade de pôr fim às relações extraconjugais:

A pesquisadora Elizabeth Myles reuniu num livro uma série de depoimentos de mulheres americanas que experimentaram o Viagra - e adoraram. Entre os relatos está o de uma sexagenária que, sob os efeitos do remédio, logrou reconquistar na cama o marido que se engraçava com uma 'beldade' de seus 50 anos (jornal culto). 
${ }^{39}$ Featherstone, em referência aos autores e discussões clássicas acerca do consumo, argumenta que este supõe uma manipulação ativa de signos: "Isso se torna central na sociedade capitalista tardia, onde o signo e a mercadoria juntaram-se para produzir a 'mercadoria-signo'. A autonomia do significante, mediante a manipulação dos signos na mídia e na publicidade, por exemplo, significa que os signos podem ficar independentes dos objetos e estar disponíveis para uso numa multiplicidade de relações associativas" (FEATHERSTONE, 1995, p. 33). 40 Segundo o jornal popular, "Viagra: um bom remédio contra a crise". Em vários outros momentos, a linguagem mercadológica para tratar do remédio não é disfarçada. Diz-se que a indústria farmacêutica percebe que a esfera da sexualidade pode ser rentável e as notícias destacam que as ações da Pfizer não param de subir desde o lançamento do remédio. As reportagens tratam sempre do preço da pastilha e das restrições de consumo para os que têm pouco dinheiro.

${ }_{41} \mathrm{Ou}$ mesmo quando algum empreendimento ia bem se dizia nos jornais: "O negócio é um Viagra. Cresceu 40\% em 1998" (jornal culto). Chegou-se até a comentar que o remédio levantaria a indústria pornográfica, facilitando o trabalho dos atores (jornal popular). Além disso, aumentaria o movimento dos motéis e a demanda por consulta com urologistas.

42 FOUCAULT, 1977.

\section{O Viagra como metáfora da vida cotidiana}

As indicações de uso do Viagra nos jornais parecem extrapolar a esfera da sexualidade e da saúde. O remédio é reportado como panaceia para todo e qualquer problema da vida social. A 'espetacularização' é tanta que em determinadas matérias o medicamento não é o objeto de discussão em si, sendo empregado apenas como metáfora de outros acontecimentos e demonstrando a centralidade do sexo na vida social. Assume a forma de um signo catalisador de vários significados, um chamariz e um veículo sintetizador dos principais fatos sociais do momento. ${ }^{39}$ Dessa forma, surge em meio às discussões sobre a economia nacional, ${ }^{40}$ a seleção brasileira de futebol ou a indústria de moda parisiense. A alusão ao medicamento aparece como solução para a instabilidade, decadência ou fragilidade. ${ }^{41}$

É certo que as matérias jornalísticas sobre o Viagra evocam, direta ou indiretamente, o tema das falhas sexuais. Utilizando o argumento de Michel Foucault, ${ }^{42}$ vemos a "colocação do sexo em discurso": as formas em que o sexo se eleva ao plano discursivo, os canais pelos quais é transmitido e os significados que operam. Nesse sentido, médicos ou sexólogos aparecem como as principais referências na produção desses discursos, mas não os únicos. Os pontos de vista que sustentam tais discursos nos jornais são diversos, envolvendo o analista econômico, o colunista social ou de esportes, entre outros profissionais.

O assunto não se restringe às sessões de saúde. Não obedece à lógica de recorte por grandes temáticas. É tratado em todo o jornal. A imprensa teve o papel fundamental de traduzir os registros biomédicos constituintes do medicamento para uma linguagem cotidiana, cujos códigos eram os eventos da vida social naquele momento. O Viagra, desde o início, é tratado como um tema não exclusivo do setor biomédico ou de saúde; sobretudo, envolve uma consideração dos processos fundamentais do funcionamento social. As representações ao redor do Viagra extrapolam comentários afeitos ao campo científico. O recurso à eficácia do medicamento foi utilizado, por exemplo, para comentar dois notáveis episódios do ano de 1998, concomitantes ao lançamento do Viagra no Brasil. Associado à possibilidade de 'vitória' ou 'fracasso' na Copa do Mundo, o Viagra é citado em crônica do jornal culto: "Chorar amargo nas margens do [rio] Sena resultará em um exercício estéril, vai ser como um viagra que não deu certo".

Outras reportagens na seção de esportes criticam o técnico da seleção brasileira, Zagallo, fazendo trocadilhos entre seu 'desempenho' sexual e como técnico: "Sabe o 
que disse o Viagra ao técnico Zagallo? Agora você vai ter que me engolir!" (frase utilizada anteriormente pelo técnico, ao confirmar-se que ele seguiria como técnico da seleção brasileira e que posteriormente se tornou bordão). Aparece também como indicação para os jogadores identificados como 'fracos'. Um dos jogadores bem-sucedidos no campeonato, Ronaldo, contrariando as previsões negativas sobre recuperação de uma cirurgia no joelho, foi assim retratado: “... se aquela patada [agressão do jogador da equipe rival] pega o nosso Ronaldinho em cheio, nem Viagra dava jeito".

Em relação à política, não faltaram referências ao medicamento. Em ano de eleições presidenciais, ícones políticos não estiveram imunes às piadas e críticas. No jornal culto noticiava-se que,

em 1994, ele foi eleito em nome da estabilidade da moeda [...]. Agora [Fernando Henrique] terá dificuldades para justificar um projeto baseado numa estagnação econômica de duração imprevisível. Se essa circunstância levar a eleição a um segundo turno, ganha todo mundo. No mínimo, sua campanha e seu ministério terão que engolir alguns tabletes de Viagra.

\section{Considerações finais}

Que sentido a entrada do Viagra no mercado brasileiro, facultada em grande parte pelos meios de comunicação de massa, confere às novas sensibilidades em termos das falhas sexuais? Para além do mundo biomédico e farmacêutico, o Viagra foi um fenômeno que adquiriu conotações mais amplas. Transformou-se em um acontecimento na consciência dos atores sociais e, de um modo geral, cristalizou as relações que se instauram a respeito. Toda a celeuma evocada para elevar o Viagra a tema de primeira ordem reedita dilemas antigos acerca da sexualidade e da relação com o masculino. Ao mesmo tempo, a massificação dessas informações atuou também no sentido de banalizar certos aspectos da masculinidade e do vigor sexual. O problema passou a ser visto mais como um reflexo dos estilos de vida e dos cuidados de si, assumindo um sentido particular de saúde. Restaurou um projeto antigo de demonização da impotência sexual, resgatando conflitos antigos e difusos sob uma nova roupagem. Intensificou-se o debate, ofereceram-se novos matizes, demarcou-se explicitamente o que concernia ao subalterno e ao dominante, e foi divulgado que deter as características dominantes era acessível (ao menos no plano simbólico, pois no material o panorama se apresenta de modo mais complicado) a todos os que agora se encontram na posição desprivilegiada, não apenas em termos da 
${ }^{43}$ DEL PRIORE, 2001, p. 100-101.

${ }^{44}$ Sérgio CARRARA, 1997. masculinidade, mas também da expressão da juventude.

Encontramos nas reportagens a pressão por um desempenho da virilidade a qualquer custo. Não importa o alto preço das pílulas, o risco de vida para os que sofrem de problemas de pressão e do coração e menos ainda a tentação de uma overdose. A honra e a manutenção de sua virilidade sobrepassa todos os riscos, que inclusive se incluem no rol das suas vicissitudes. Evoca-se com muita naturalidade a sexualidade masculina como naturalmente excessiva; a disposição para o sexo estaria compondo uma essência do ser homem, mesmo que o corpo não respondesse a tal intento.

Segundo as matérias, a impotência é um problema, o que não é uma novidade no universo cultural brasileiro. Como bem demonstra Mary Del Priore em seu estudo sobre a esterilidade no Brasil colonial, "Trezentos anos atrás [...] o Viagra era de outra natureza. A angústia, contudo, nascida da obrigação de virilidade, já estava profundamente arraigada em nossa cultura". ${ }^{43}$ Na história recente, 0 surgimento da sexologia e a tentativa de instauração da andrologia no Brasil sugerem de igual modo a preocupação com os problemas sexuais masculinos. ${ }^{44}$ Evidentemente, a impotência sexual ou simplesmente o que poderíamos considerar como as falhas sexuais masculinas não podem ser tratadas como concepções unívocas de um mesmo fenômeno. O tema persiste a despeito do tempo, com ênfases e sob imperativos e agendas sociais particulares.

O discurso jornalístico sobre o Viagra situa o debate a respeito da potência sexual/virilidade nos marcos de uma lógica mercadológica, tratando-a como um bem que pode ser imediata e rapidamente reestabelecido através do consumo da tecnologia.

As reportagens não aludem apenas ao modelo médico em torno das falhas sexuais. Assim, vamos encontrar nas diferentes matérias um detalhamento científico e um projeto patologizante acerca dos fracassos da vida sexual, indicando muitas vezes benevolência com os que sofrem 'o mal da disfunção erétil'. Mas também encontramos um conjunto de discursos que apelam para representações populares e uma moral de vergonha sobre tais falhas. O debate que norteou o surgimento do Viagra na sociedade brasileira afiançou-se numa lógica conservadora tanto no que concerne às tensões sobre as desigualdades e representações de gênero, como nas concepções de sexualidade. É surpreendente como a apresentação do remédio esteve fundamentada em prerrogativas extremamente tradicionais sobre o masculino, na sua relação com o feminino e no tipo de desempenho sexual ideal para os homens. O anacronismo que identificamos se dá pelo notável contraste que as 
imagens sobre o Viagra fazem com a forte presença dos questionamentos de gênero oriundos do universo feminista, dos movimentos de emancipação homossexual, dos ecos gerados nas práticas e concepções de saúde pública e das diversas ações comunitárias, presentes no cotidiano brasileiro no final dos anos 90 . O discurso que construiu 0 Viagra apostou numa linha, digamos, neoconservadora, segundo a qual o homem deve ser valorizado prioritariamente por sua potência sexual, por ditar e comandar as relações sexuais e por reiterar a supremacia da lógica heterossexual, e que apresenta a mulher como mera expectadora ou participante passiva nas relações sexuais. Isso dito em um momento em que no país se multiplicavam as reflexões críticas sobre o homem e a masculinidade e propostas de intervenção, e se fortaleciam os mecanismos para garantir direitos sexuais e reprodutivos.

Mesmo com o caráter paradoxal com que foram construídas as conotações em torno do Viagra, esse medicamento representa hoje um elemento muito importante na composição do universo sexual brasileiro. A mídia desempenhou, nesse sentido, um papel primordial. Os meios de comunicação, por meio desse remédio, validaram um projeto moderno segundo o qual a sexualidade ocupa um espaço significativo na vida dos sujeitos e na produção de verdades sobre si, ao mesmo tempo que apostaram em representações tradicionais sobre as relações de gênero e a sexualidade.

\section{Referências bibliográficas}

ADORNO, Sergio. "Violência e o mundo da recepção televisiva". Novos Olhares, ECA/USP, ano 1, n. 1, 1998. 1998. Entrevista.

AZIZE, Rogério. "Masculinidades, Viagra e saúde". RIAL, Carmem; TONELI, Maria Juracy Filgueiras (Orgs.). Genealogias do silêncio: feminismo e gênero. Florianópolis: Editora Mulheres, 2004. p. 171-181.

BAJOS, Natalie; BOZON, Michel. "La sexualité à l'épreuve de la medicalisation: le Viagra". Actes de la Recherche en Sciences Sociales (Sur la Sexualité), n. 128, p. 34-37, 1999.

BÉJIN, André. "O poder dos sexólogos e a democracia sexual”. In: ARIÉS, Phillipe; BÉJIN, André (Orgs.). Sexualidades ocidentais. 3. ed. São Paulo: Brasiliense, 1987. p. 236-254.

BLANCHET, Alain; GOTTMAN, Anne. L'Enquête et les méthodes: l'enttretien. Paris: Éditions Nathan, 1992.

BOURDIEU, Pierre. "A influência do jornalismo". In: Sobre a televisão. Rio de Janeiro: Jorge Zahar Editor, 1986. p. 99-120. 

2000.

BOZON, Michel. Sociologia da sexualidade. Rio de Janeiro: Editora FGV, 2004.

BRIGEIRO, Mauro. Rir ou chorar? Envelhecimento, sexualidade e sociabilidade masculina. 2000. Dissertação (Mestrado em Saúde Coletiva) - Instituto de Medicina Social, Universidade do Estado do Rio de Janeiro.

. "Envelhecimento bem-sucedido e sexualidade: relativizando uma problemática". In: BARBOSA, Regina et al. (Orgs.). Interfaces: gênero, sexualidade e saúde reprodutiva. Campinas, SP: Editora da Unicamp, 2002. p. 171-206.

CARRARA, Sérgio. "Sexualidade e sexologia no Rio de Janeiro de entre-guerras". Cadernos do IPUB, n. 8, p. 113-128, 1997.

CONNEL, Robert. "El imperialismo y el cuerpo de los hombres". In: VALDES, Teresa; OLAVARÍA, José (Eds.). Masculinidady equidad de género en América Latina. Santiago de Chile: Flasco-Chile, 1998. p. 76-89.

DA MATTA, Roberto. "Para uma teoria da sacanagem: uma reflexão sobre a obra de Carlos Zéfiro". In: MARINHO, Joaquim (Org.). A arte sacana de Carlos Zéfiro. Rio de Janeiro: Marco Zero, 1983. p. 29-30.

DEBERT, Guita Grin. "A invenção da terceira idade e a rearticulação de formas de consumo e demandas políticas". Revista Brasileira de Ciências Sociais, v. 12, n. 34, p. 3956, 1997.

DEL PRIORE, Mary. "Homens e mulheres: o imaginário sobre a esterilidade na América portuguesa". História, Ciências, Saúde-Manguinhos, v. 3, n. 1, p. 98-112, 2001.

ENGLER, Yves. "The Pharmaceutical Drive to Drug." Humanist, v. 63, n. 3, 2003. p. 39-40.

FARQUHAR, Judith. Appetites: Food and Sex in Post-Socialist China. Durham, NC: Duke University Press, 2002.

FEATHERSTONE, Michael. Cultura de consumo e pósmodernismo. São Paulo: Studio Nobel, 1995.

FOUCAULT, Michel. História da sexualidade I: a vontade de saber. Rio de Janeiro: Graal, 1977.

GALVÃO, Jane. AIDS no Brasil. Agenda de construção de uma epidemia. Rio de Janeiro: ABIA; São Paulo: Ed. 34, 2000.

GIAMI, Alain. "La medicalisation de la sexualité: aspects sociologiques et historiques". Andrologie, v. 8, n. 3, p. 383-390, 1998.

HEPWORTH, Mike, and FEATHERSTONE, Mike. "The Male Menopause: Cultural Reconstruction." In: NETTLETON, Sarah, and WATSON, Jonathan (eds.). The Body in Every Day Life. London and New York: Routledge, 1999. p. 276-301. 
HERZLICH, Claudine; PIERRET, Janine. "Uma doença no espaço público: a Aids em seis jornais franceses". PHYSIS Revista de Saúde Coletiva, v. 2, n. 1, p. 7-35, 1992.

LAQUEUR, Thomas. Inventando o sexo: corpo e gênero dos gregos a Freud. Rio de Janeiro: Relume-Dumará, 2001.

LUZ, Madel. As instituições médicas no Brasil: instituição e estratégia de hegemonia. Rio de Janeiro: Graal, 1979.

MAKSUD, Ivia. Sexualidade e mídia: uma análise sócioantropológica do discurso jornalístico. 2000. Dissertação (Mestrado em Saúde Coletiva) - Instituto de Medicina Social, Universidade do Estado do Rio de Janeiro.

PARKER, Richard. Corpos, prazeres e paixões: a cultura sexual no Brasil contemporâneo. São Paulo: Best Seller, 1991.

SERRA, Antonio. O desvio nosso de cada dia: a representação do cotidiano num jornal popular. Rio de Janeiro: Dois Pontos, 1986.

[Recebido em novembro de 2007 e aceito para publicação em abril de 2008]

The Emergence of Viagra in the Brazilian Public Scenario: Discourses on Body, Gender and Sexuality in the Media

Abstract: This work proposes an anthropological reflection on the images and discourses of the body and the sexuality in the Brazilian society, focusing on a particular social phenomenon: the emergence of the Viagra in the national public scenario. This article explores the connotations constructed and confirmed by the Brazilian media press about this drug. Two Brazilian newspapers belonging to the same publisher but aimed at different publics were analyzed from April 1998 to April 1999, period that corresponds to the beginning - and apex - of the debate on the Viagra in the country. The discussion focuses on the symbolism and discursive strategies utilized by the newspapers when presenting this medication to the general public. This article also draws the attention to an appeal to traditional logics of gender, despite a contemporary scenario of issues concerning the relationships among the sexes and the sexuality.

Key Words: Sexuality's Medicalization; Gender; Body; Aging; Media. 